\title{
University College London Hosts 4th BACG Photochemical Processing Workshop
}

University College London hosted the Fourth Photochemical Processing Workshop of the British Association for Crystal Growth (BACG) April 21, 1989. The workshop followed the same successful format of the previous meetings with brief up-tothe-minute contributions. This year, 17 talks were presented, more than in previous years. Although the earlier meetings were envisaged as an annual gathering of the United Kingdom's photochemical processing community, the last two have attracted an increased, and welcome, involvement from other European countries, including collaboration with the European-MRS.

The host and program chairman was Ian W. Boyd, who founded the laser processing group in the Department of Electrical Engineering at University College London. The laser processing group participates in the London University Interdisciplinary Research Centre (IRC) in semiconductors and optical materials. Coorganizer and treasurer was Richard Jackman, while Stuart Irvine and David Haigh contributed greatly in the overall organization within the scientific committee.

The largest session covered deposition of semiconductors, from amorphous silicon to $\mathrm{GaAs}$ and $\mathrm{ZnSe}$. S.C. Deane and W.I. Milne (Cambridge University) described photochemical vapor deposition of thin film transistors. The internal lamp technique was used where a hydrogen discharge in the upper part of the cell illuminates the $\mathrm{SiH}_{4}$ reactant gas in the lower section. Using $1 \mathrm{mbar}$ total pressure and a substrate temperature of $250^{\circ} \mathrm{C}$, a growth rate of $0.7 \AA / \mathrm{s}$ was achieved. The amorphous $\mathrm{Si}: \mathrm{H}$ thin films were flat to within 5-10 $\AA$. The thin film transistor performance was comparable for the internal lamp and plasma deposition, with poorer performance if an external lamp was used.

S. Rolt and K.G. Snowden (STC Technology Ltd.) reported on the problems associated with low-temperature GaAs epitaxy by laser-induced deposition. Difficulties with maintaining a clean UV window free from reaction products were overcome with careful reactor cell design and the incorporation of a purge gas. $\mathrm{GaAs}$ films were grown onto AlGaAs buffered GaAs substrate at temperatures in the 350$450^{\circ} \mathrm{C}$ range. Trimethyl gallium and arsine were decomposed using a $248 \mathrm{~nm}$ excimer laser at $100 \mathrm{~mJ} / \mathrm{cm}^{2} /$ pulse. The films were epitaxial but displayed some twinning. Some encouraging assessment came from secondary ion mass spectroscopy, which indicated that the carbon concentration was below $5 \times 10^{17} \mathrm{~cm}^{3}$. J. Hopkins et al. (Heriot-Watt University) described an alternative approach to GaAs laser deposition. An argon ion laser beam was focused onto a substrate and scanned across the surface. Decomposition of trimethyl gallium and arsine occurred on the substrate due to laser heating. A continuous $10 \mu \mathrm{m}$ wide stripe was deposited using $4 \mathrm{w}$ power and V:III ratio of 15:1.

J.E. Hails et al. (RSRE) described the significant properties of precursors for successful laser-induced epitaxy of CdTe. For selected-area epitaxy the precursors must be thermally stable on the substrate but readily decompose in UV illumination. UV absorption spectra were reported for a number of alternative tellurium precursors and the absorption cross sections compared for relevant laser wavelengths. Selected-area epitaxy of CdTe onto a GaAs substrate at $300^{\circ} \mathrm{C}$ was achieved using illumination at $257 \mathrm{~nm}$ from a frequency doubled argon ion laser. The precursors were dimethyl cadmium and diethyl telluride, both having absorption cross sections $\sim 0.1$ $\AA^{2}$ at this wavelength.

Another contribution on II-VI deposition was given by John Simpson and J.O. Williams, (University of Manchester Institute of Science \& Technology - UMIST) on laser-induced deposition of $\mathrm{ZnSe}$. Two different techniques were described and contrasted: (1) ArF excimer laser decomposition of diethyl selenide and dimethyl zinc, and (2) ArF excimer-laser-generated plasma on a solid ZnSe target. A novel approach was used in the photolytic deposition case to avoid heterogeneously nucleated dust. A $400 \mathrm{~V}$ ion trap on the window was used to collect dust removed by the laser pulses. The advantage of the laser-induced plasma source technique is that the charged atoms could be steered electrostatically, preventing ablated particles from falling on the substrate.

The final paper in the semiconductor deposition session had a truly international flavor. Chris Kiely (Liverpool University) described work he carried out with Garry Eden at the University of Illinois on epitaxial Ge films on GaAs. An excimer laser was used at $193 \mathrm{~nm}$ to decompose $\mathrm{GeH}_{4} \cdot \mathrm{NH}_{3}$ was used as a photosensitizer to form $\mathrm{Ge}_{2} \mathrm{H}_{6}$, which could pyrolyze on the substrate at $280^{\circ} \mathrm{C}$.

Three papers were presented on the deposition of metals, insulators, and su- perconductors. Mike Jubber (Heriot-Watt University) presented recent results on gold photothermal deposition onto $\mathrm{SiO}_{2}$ coated silicon. High purity gold lines were written using the precursor $\mathrm{AuMe}\left(\mathrm{Et}_{3} \mathrm{P}\right)$ for a range of laser powers and line widths from 1 to $40 \mu \mathrm{m}$. Stephen Lane (Alcan International) and M. Green (Imperial College) took a photochemical approach to deposit gallium from $\mathrm{GaI}_{3}$. The initial stage was a thermal decomposition to yield $\mathrm{GaI}$, which adsorbed onto the substrate and then photodecomposed to leave a gallium film. Kevin Mackey (RSRE) used fluorinated calcium acetyl acetonate as a precursor for photo-assisted growth of $\mathrm{CaF}_{2}$. A mercury lamp was used to photodissociate the precursor and deposit thin films of polycrystalline $\mathrm{CaF}_{2}$ onto (100) $\mathrm{GaAs}$ at $350^{\circ} \mathrm{C}$.

A contribution with important technological applications for laser ablation of superconductors was made by Martin Brown et al. (University College London). Laser ablation can be used as a reliable source for this film deposition but the beam is highly directional, which makes the deposition of uniform thickness very complicated. By optimizing the geometry with the beam striking the target at an incidence of $25^{\circ}$, uniform films over $2 \mathrm{~cm}$ diameter were obtained.

John Foord et al. (University of Oxford) used surface spectroscopic and molecular beam studies to study the decomposition of trimethyl aluminum on silicon and aluminum surfaces. A multilayer adsorbate was formed at $100 \mathrm{~K}$ from which a chemisorbed molecular dimer developed on the Si(100) surface. Decomposition products were investigated as these films were warmed, as was the nature of the remaining film. This was compared with photolysis of the film which is technologically important for prenucleation of metallization. It was discovered that a polymeric film formed, which requires some pyrolysis to form the metallic film. Richard Jackman et al. (University College London) continued the theme of surface studies in discovering the role of photoenhancement. In photo-etching, understanding the surface mechanisms can lead to better etch depth control. The use of techniques such as thermal desorption studies (TDS) and $x$-ray photoelectron spectroscopy (XPS) was described.

P.A. Goulding et al. (UMIST) showed how surface studies could be used to study the surface species during photochemical 
etching of GaAs. $\mathrm{CH}_{2} \mathrm{I}_{2}$ was found to be particularly effective in removing surface arsenic, and a possible scheme for combining this with laser selected-area etching was proposed.

Martyn Pemble (UMIST) discussed some recent experiments on surface second harmonic generation (SHG). A surprising result was observed for exposure of an arsenic rich GaAs (100) surface to trimethyl gallium. Instead of reducing the SHG signal by masking the surface, an increase was observed which was attributed to charge transfer effects.

T.S. Baller and co-workers (Philips Research Laboratories, Eindhoven) used a time-of-flight mass spectrometer to investigate laser-enhanced chlorine etching of copper surfaces. By changing the laser power density or $\mathrm{Cl}_{2}$ pressure, different regimes of surface coverage and chlorine diffusion were obtained. Optical etching conditions were proposed for photoetching of copper.

The final papers covered the thermal processing of materials using lasers as the energy sources and helped to round off a diverse and fascinating program.

E.J. Petit et al. (Laboratoire Interdisciplinaire de Spectroscopies Electroniques, Belgium) with co-workers (from Centre d'Electronique de Montpellier) used pulsed UV laser annealing of GaSb single crystals to prepare oxide layers at low temperatures. T. Wather (University of Stuttgart) with co-workers (from Newcastle
Upon Tyne Polytechnic) gave an account of the preparation of the solar cell material CuInSe ${ }_{2}$ onto glass substrates by laser heating of stacked layers of the component elements. Single-phase chalcopyrite films were reported.

In recognition of the increased international interest in these annual gatherings, next year will feature an expanded, more fully international BACG photochemical processing workshop and will again be held at the excellent facilities at University College London, with increased collaboration through the E-MRS Network on Photochemical Processing and the European Economic Community's Science Program.

Stuart J.C. Irvine

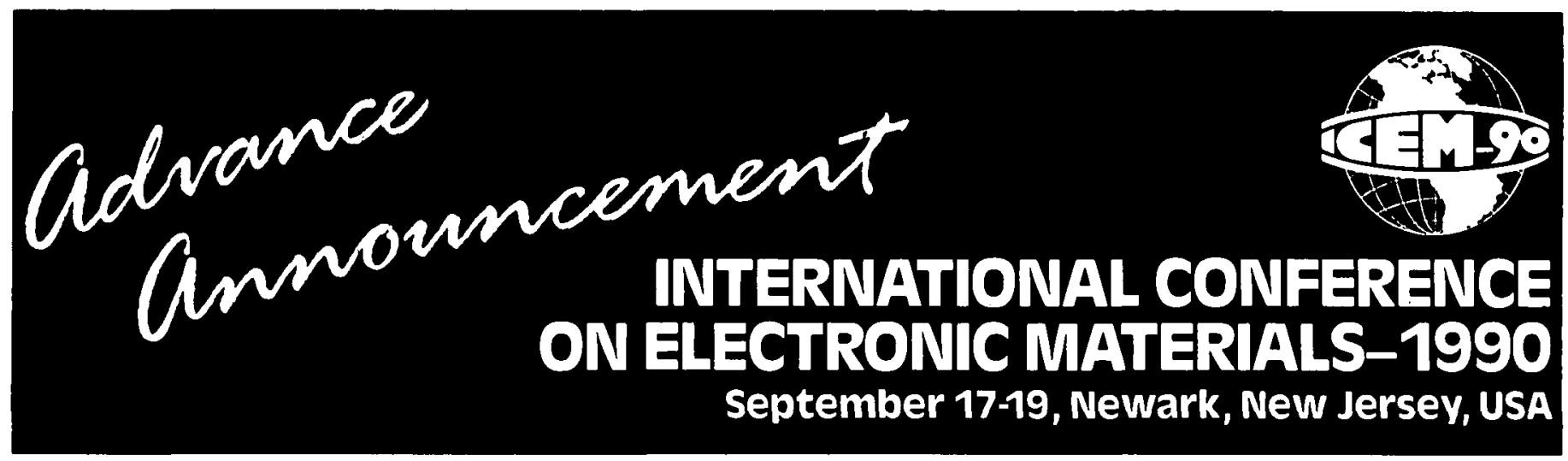

The second International Conference on Electronic Materials (ICEM) will be held September 17-19, 1990 in Newark, New Jersey adjacent to the Newark international Airport. This biennial conference provides the opportunity for investigators in the field of advanced electronic materials to discuss recent progress and future trends. Following the successful format of the first conference, there will be no parallel sessions, and the technical sessions will consist of oral and poster sessions.

ICEM-90 is sponsored jointly by the Materials Research Society, the European Materials Research Society, and the Japan Society of Applied Physics.

Conference topics will include:

- SUPERCONDUCTING DEVICE MATERIALS

- MATERIALS FOR OPTOELECTRONICS

- ADVANCED THIN FILM TECHNOLOGY

- DIAMOND FOR ELECTRONIC AND OPTICAL APPLICATIONS

The Program committee will be pleased to consider abstracts on the topics listed above. To receive further ICEM-90 announcements, Call for Papers and program information regarding ICME-90, contact: Jane stokes ICEM-90, Materials Research Society, 9800 McKnight Road, Pittsburgh, PA 15237, telephone (412) 367-3003,

fax (412) 367-4373.

\section{munumenen CONFERENCE DETAILS}

LOCATION: The conference will be held adjacent to the Newark, New Jersey International Airport. Complimentarv shuttle service will be available from the airport to the conference hotel.

PROCEEDINCS: A proceedings will be published; camera ready manuscripts will be due the first day of the conference and refeered at the meeting. Instructions and templates for the preparation of the manuscripts will be sent with notices of acceptance of papers.

\section{-numananan RELATED CONFERENCES}

September 9-14, 1990: The 7th International Conference on Ion Beam Modification of Materials (IBMM) will be held September 9-14, 1990 in Knoxville, Tennessee immediately prior to ICEM-90. This biennial confer ence will bring together investigators in the field of materials modification of ion beams to discuss recent progress and future trends. For further information, contact IBMM-90, P.O. Box 2008, MS 6033, Oak Ridge, TN 37831-6033, USA; FAX (615) 574-4143.

September 23-27, 1990: The 2nd International Conference on New Diamond Sciences and Technology (2nd ICNDST) will be held in Crystal Clty, Virginia (near Washington D.C.) following ICEM-90. For further infoi mation, contact Russell Messier, Professor of Engineering Science \& Mechanics at Pennsylvania State University, 265 Materials Research Laboratory, University Park, PA 16802, (814) 865-3704, FAX (814) 865-2326. 


\section{EQUIPMENT EXHIBIT at the 1989 MRS Fall Meeting}

As part of the 1989 MRS Fall Meeting in Boston, a major equipment exhibit will display analytical and processing equipment closely paralleling the nature of the technical symposia and short courses. The exhibit will be conveniently located on the third floor of the Boston Marriott Hotel/Copley Place.

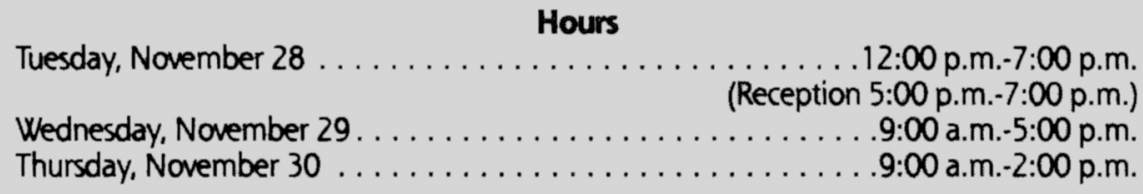

\section{Exhibitors \\ (as of September 13, 1989)}

Academic Press, Inc.

Advanced Materials Engineering Research

Aixtron $\mathrm{GmbH}$

Alcatel Vacuum Products, Inc.

American Chemical Society

American Institute of Physics

Amplifier Research

Anatech Ltd.

APD Cryogenics Inc.

Aries/QEI

ASTeXJApplied Science \& Technology

ATM, Inc.

Balzers

Beam Alloy Corporation

Blake Industries, Inc.

Edmund Buehler

$\mathrm{GmbH} \&$ Co.

Cahn Instruments Inc.

Cameca Instruments, Inc.

Ceramaseal

Chapman and Hall

Commonwealth Scientific Corp.

CVC Products, Inc.

Denton Vacuum, Inc.

Duniway Stockroom Corporation

E.A. Fischione Instrument Mfg.

Edwards High Vacuum International

EGEG Princeton Applied Research

Elsevier Science Publishing Co., Inc.

Charles Evans \& Associates

FEI Company

Gatan, Inc.

Goodfellow Metals Cambridge Ltd.

Granville-Phillips Co.

High Vacuum Apparatus Mfg., Inc.

Hitachi Scientific Instruments

HPS Div. of MKS Instruments Inc.

Huntington Laboratories

Image Micro Systems, Inc.
Implant Sciences Corporation

Inel Inc.

Innovative Technology, Inc.

Instruments SA, Inc.

International Scientific Instruments

Ion Tech, Inc.

Janis Research Company

JCPDS-ICDD

JEOL U.S.A., Inc.

Kaiser Systems, Inc.

Keithley Instruments

Kevex Instruments, Inc.

Kimball Physics, Inc.

Kratos Analytical, Inc.

Lake Shore Cryotronics, Inc.

Lambda Physik, Inc.

Lehighton Electronics, Inc.

Kurt J. Lesker Company

Leybold Inficon

Leybold Vacuum Products

Materials by Metron

McAllister Technical Services

MDC Vacuum Products Corporation

Microscience, Inc.

MKS Instruments Inc.

MMR Technologies, Inc.

National Electrostatics Corp.

Neslab Instruments

Netzsch Incorporated

NGS Associates, Inc.

Nicolet

North Eastern Analytical Corp.

Omicron Associates

Oxford Instruments

Oxford University Press

Peabody Scientific

Pergamon Press

Perkin-Elmer Corporation

Philips Electronic Instruments Co.

Physicon Corporation
Plasma Technology

Plenum Publishing Corporation

Princeton Gamma-Tech, Inc.

Princeton Instruments

Process Products Corporation

Quantachrome Corp.

Quantum Design, Inc.

RHK Technology, Inc.

Rigaku/USA, Inc.

RMC-Cryosystems Inc.

Rudolph Instruments

Rudolph

Research Scientific Instruments

Scintag, Inc.

Siemens Analytical X-Ray

South Bay Technology, Inc.

Spectramass, Inc.I

Spectra Instruments Div.

Spectra-Tech Inc.

Spire Corporation

Springer-Verlag New York Inc.

Structure Probe, Inc./SPI Supplies

Sula Technologies

Superconductive Components, Inc.

Sycon Instruments, Inc.

Tencor Instruments

Thermionics Laboratory

Ultra High Vacuum Instruments, Inc.

Vacuum Barrier Corp.

Varian/Vacuum Products

VAT, Inc.

VCR Group, Inc.

VG Instruments, Inc.

Virginia Semiconductor, Inc.

Voltaix, Inc.

Walff Associates

Waterloo Scientific

Wavemat, Inc.

John Wiley \& Sons

Carl Zeiss, Inc.

SEE AD IN THIS ISSUE. 